\title{
Relationship between Body Mass Index and Thyrotropin in Euthyroid Women: Differences by Smoking, Race and Menopausal Status
}

\author{
Amanda de Moura Souza Rosely Sichieri \\ Department of Epidemiology, Institute of Social Medicine, State University of Rio de Janeiro, Brazil
}

\section{Keywords}

Body mass index · Smoking habits - Thyroid hormones . Menopause - Thyrotropin · Ethnic differences

\section{Summary}

Objective: To evaluate potential effect modifications on the association between BMI and thyrotropin (TSH) by smoking, race, and menopausal status among euthyroid women. Methods: A cross-sectional population-based study was carried out in the city of Rio de Janeiro, Brazil, in 2004-2005. Households $(1,500)$ were selected using three-stage probability sampling. A sample of 1,084 women aged 35 years or older and with $\mathrm{TSH}$ values within the reference range $(0.3-4.0 \mathrm{mlU} / \mathrm{l})$ was investigated. Weight and height were measured at household and blood collected for serum TSH and anti-thyroperoxidase (anti-TPO) antibody analysis. Results: Overall, BMI was positively and significantly associated with serum TSH ( $\beta=0.87 ; p=0.001)$. This association was modified by smoking, race, and menopausal status $(p<0.05)$. Adjusted regression coefficients were 1.78 versus 0.58 comparing smokers with non-smokers, 1.39 for Blacks compared to 0.79 for Non-Blacks, and 0.70 for women in menopause compared to 1.04 for premenopausal women. The percentage of high anti-TPO (greater than $35 \mathrm{Ul} / \mathrm{ml}$ ) was $8.8 \%$, and the association between $\mathrm{TSH}$ and BMI was no longer significant in this group. Conclusion: BMI was positively associated with serum TSH specifically in its normal range, but only for those women who tested negative for anti-TPO. Smoking and race are negatively associated with anti-TPO, possibly explaining the effect modification observed.

\section{Introduction}

Although overt thyroid dysfunction is associated with weight changes, recent reports on the relationship between BMI and serum thyrotropin (TSH) in euthyroid subjects have shown controversial results. Population-based studies carried out in Denmark and Norway demonstrated a positive and significant association between BMI and TSH in subjects with normal thyroid function $[1,2]$. In contrast, studies performed with euthyroid subjects in Australia and the UK found no significant association between BMI and TSH [3, 4].

A possible explanation for the lack of association between BMI and TSH in different studies is the influence of factors such as smoking and race, which could modify the relationship between BMI and TSH, mainly because these factors are associated with the presence of anti-TPO [5, 6]. We did not find any study in the literature which controlled for both smoking and race when investigating the association between BMI and TSH.

Few studies have evaluated a possible effect modification by smoking on the association between BMI and TSH. Nyrnes et al. [2] in a population study in Norway, reported a positive relationship between BMI and TSH only among non-smokers. On the other hand, Makepeace et al. [3], in a communitybased study performed in Australia, found no significant association in any of the smoking groups.

Race is independently associated with serum TSH, as shown in a population study performed in Brazil [6]. In this study, TSH levels in Brazilian Black women were $22 \%$ lower than the levels of their White counterparts, a statistically significant difference. In addition, other reports found higher TSH levels in White people [7,8].

Also, there are no data regarding a possible effect modification of menopause on the association between BMI and

Amanda de Moura Souza

Department of Epidemiology, Institute of Social Medicine

State University of Rio de Janeiro

Rua São Francisco Xavier, 524, $7^{\circ}$ andar, Bloco E. Cep 20550-900, Rio de Janeiro, RJ, Brazil Tel. +55 21 2334-0504, Fax -2152

amandamoura@msn.com 
TSH. Race and menopausal status are associated with BMI, with a higher prevalence of obesity among Blacks and among postmenopausal women [9], indicating that all these factors could be important confounding variables along with age [10].

In relation to menopausal status, postmenopausal women treated with conjugated estrogen showed an increase in TSH levels during a 6-week treatment period [11]. Moreover, a study in ovariectomized rats showed an increase in TSH concentrations when compared with animals with intact ovaries [12].

We therefore aimed at evaluating potential effect modifications on the association between BMI and TSH by smoking, race and also by menopausal status.

\section{Material and Methods}

\section{Sample Design and Subjects}

A population-based study was conducted in the city of Rio de Janeiro, Brazil, in 2004-2005. From a sample of 1,500 women aged 35 years or older, 1,298 agreed to participate. Details of the study have been previously published [6]. Sample selection was based on a three-stage cluster design. In the first stage, 100 primary sample units (PSU) were selected by systematic sampling with probability proportional to size, based on the operational geographical units of the Brazilian 2000 Census. In the second stage, one woman was selected from each household. Pregnant and lactating women were not included. For the present study, we excluded women with either hyper- or hypothyroidism, i.e. women presenting with TSH values greater than $4.0 \mathrm{mIU} / 1$ or lower than $0.30 \mathrm{mIU} / \mathrm{l}$. In addition, women reporting treatment with thyroid hormone were excluded, leaving 1,100 women for analysis. In 16 women there were missing values for BMI, yielding a final sample of 1,084 women.

12 women were taking drugs that could affect thyroid function (amiodarone $(n=7)$ and lithium $(n=5))$. These women were not excluded because their serum TSH values were within the normal range of TSH.

\section{Measurements}

Serum TSH was measured by microparticle enzyme immunoassay (Abbott Laboratories, Abbott Park, IL, USA). The assay had a variation coefficient of $10 \%$ and a detection limit of $0.05 \mathrm{mIU} / \mathrm{l}$, with a normal range of 0.3-4.0 mIU/l. Women were also tested for presence of anti-TPO by chemiluminescence (titer > $35 \mathrm{UI} / \mathrm{ml}$; kit: Immulite, Los Angeles, CA, USA).

Free thyroxine (T4) was measured among those women with TSH > $4 \mathrm{mIU} / \mathrm{l}$. Overt hypothyroidism was defined by serum TSH values greater than $4 \mathrm{mIU} / \mathrm{l}$ and serum free T4 $<0.7 \mathrm{ng} / \mathrm{dl}$. Subclinical hypothyroidism was established by serum TSH concentration greater than $4 \mathrm{mIU} / 1$ and lower than $10 \mathrm{mIU} / 1$ with normal value of free $\mathrm{T} 4$ (T4 $\geq 0.7 \mathrm{ng} / \mathrm{dl})$.

Body weight and height were measured by trained interviewers using standardized protocols [13]. Weight was measured to the nearest $0.1 \mathrm{~kg}$ using electronic digital scales (Plenna ${ }^{\circledR}$ ), and height was measured to the nearest $0.1 \mathrm{~cm}$ using a portable stadiometer $\left(\mathrm{Seca}^{\circledR}\right)$.

BMI was calculated as the weight $(\mathrm{kg})$ divided by the square of height in meters $\left(\mathrm{m}^{2}\right)$, and the World Health Organization classification [14] was used to categorize subjects as either overweight $\left(25.0<\mathrm{BMI}<30 \mathrm{~kg} / \mathrm{m}^{2}\right)$ or obese $\left(\mathrm{BMI} \geq 30.0 \mathrm{~kg} / \mathrm{m}^{2}\right)$.

Other variables analyzed included age, race, schooling, income, smoking, parity and menopausal status. Race was defined by the interviewer based on observation of the subject's skin color (White, Black or Mulatto). Smoking exposure status was determined based on the interview, and subjects were categorized as 'never smoker', 'former smoker' (those with any past smoking exposure) or 'current smoker.' Menopausal status was defined based on self-reported information. Women were considered to be in menopause if their menstrual periods had ceased for at least 1 year [15].

\section{Statistical Analysis}

Linear regression models were used to evaluate the association between BMI and TSH as well as possible effect modifications of this association. Although univariate analysis did not show any association of TSH with age groups, advanced age was associated with low levels of TSH. Thus, adjustments by age as a continuous variable include a quadratic term of age. Race, smoke, and menopause were considered as potential confounders and effect modifiers of the association between TSH and BMI; therefore, analysis was stratified by smoking (yes/no), menopausal status (premenopausal/postmenopausal), and race (Black/ Non-Black). Additional analysis stratified according to presence of anti-TPO was also done. All statistical analyses were performed using the survey procedure in the Statistical Analysis System software, version 9.1 (SAS Institute INC., Cary, NC, USA) taking into account the sample design effect. Logarithmic transformation of TSH was applied for linear modeling.

\section{Results}

The mean age was 53.1 years, with a standard deviation (SD) of 11.7 years. The mean BMI was $26.6 \pm 5.38 \mathrm{~kg} / \mathrm{m}^{2}$. A high prevalence of overweight $(33.5 \%)$ and obesity $(22.0 \%)$ was observed. The mean serum TSH was $1.7 \pm 0.85 \mathrm{mIU} / \mathrm{l}$.

Table 1 shows the association of TSH with other characteristics of the study population. TSH was significantly associated with race and smoking status among euthyroid subjects. $44 \%$ of the women were White, and $16.8 \%$ were Black; the proportion of smokers was $23.0 \%$, and $52.0 \%$ of the women reported being in menopause.

Due to the quadratic associations found between age and TSH (table 1), analysis of menopausal status also included the variables age and age squared. TSH was significantly associated with menopause after adjustment for age and age squared with a $\mathrm{p}=0.007$ (data not shown).

Overall, a positive and significant association was found between BMI and serum TSH $(\beta=0.90 ; p=0.02)$. This relationship remained significant after adjustment for age, age squared, race, smoking and menopause $(\beta=0.87)$ (table 2$)$.

This association was highly modified by smoking, race and menopausal status, as shown in table 3. Smoking was the strongest effect modifier of the association between BMI and TSH. One unit increase in the log of TSH (about 3 units of TSH) was associated with an increase in BMI of $1.78 \mathrm{~kg} / \mathrm{m}^{2}$. For a woman with a height of $1.60 \mathrm{~m}$, this increase corresponds to a difference in body weight of $4.5 \mathrm{~kg}$.

Additional analysis stratified according to presence of antiTPO revealed a positive and significant association between BMI and serum TSH among women negative for anti-TPO $(\beta=1.00 ; p=0.006)$. These women represent $91.2 \%$ of the study sample. In contrast, among women with levels of antiTPO greater than $35 \mathrm{UI} / \mathrm{ml}$ the association between BMI and serum TSH was no longer significant $(\beta=-0.75 ; p=0.37)$. We 
Table 1. Participant characteristics

\begin{tabular}{|c|c|c|c|c|}
\hline \multirow{2}{*}{$\begin{array}{l}\text { Participant } \\
\text { characteristics }\end{array}$} & \multicolumn{2}{|c|}{ Sample size } & \multicolumn{2}{|l|}{$\mathrm{TSH}$} \\
\hline & $\mathrm{N}$ & $\%$ & mean $\pm \mathrm{SE}$ & $\mathrm{p}$ value \\
\hline \multicolumn{5}{|l|}{ Age, years } \\
\hline $35-45$ & 336 & 29.3 & $1.59 \pm 0.05$ & $0.16^{*}$ \\
\hline $46-55$ & 367 & 32.6 & $1.69 \pm 0.05$ & \\
\hline $56-65$ & 207 & 19.5 & $1.81 \pm 0.09$ & \\
\hline 66 or more & 174 & 18.6 & $1.68 \pm 0.07$ & \\
\hline \multicolumn{5}{|l|}{ Race } \\
\hline White & 441 & 44.0 & $1.74 \pm 0.05$ & \\
\hline Mulatto & 443 & 39.2 & $1.72 \pm 0.05$ & 0.0008 \\
\hline Black & 187 & 16.8 & $1.44 \pm 0.06$ & \\
\hline \multicolumn{5}{|l|}{ Smoking } \\
\hline Never & 556 & 53.8 & $1.75 \pm 0.04$ & \\
\hline Former & 259 & 23.1 & $1.76 \pm 0.07$ & $<0.0001$ \\
\hline Current & 269 & 23.1 & $1.45 \pm 0.06$ & \\
\hline \multicolumn{5}{|l|}{ Parity } \\
\hline 0 & 113 & 12.2 & $1.56 \pm 0.08$ & $0.83 *$ \\
\hline 1 & 199 & 20.0 & $1.73 \pm 0.08$ & \\
\hline 2 & 346 & 31.7 & $1.78 \pm 0.06$ & \\
\hline 3 or more & 425 & 36.1 & $1.63 \pm 0.04$ & \\
\hline \multicolumn{5}{|l|}{ Menopausal status } \\
\hline Premenopausal & 543 & 48.2 & $1.69 \pm 0.04$ & 0.56 \\
\hline Postmenopausal & 541 & 51.8 & $1.67 \pm 0.05$ & \\
\hline \multicolumn{5}{|l|}{ Nutritional status } \\
\hline Normal & 454 & 44.5 & $1.63 \pm 0.05$ & \\
\hline Overweight & 379 & 33.5 & $1.68 \pm 0.05$ & $0.09 *$ \\
\hline Obese & 251 & 22.0 & $1.79 \pm 0.06$ & \\
\hline
\end{tabular}

also found no association between BMI and serum TSH among women with subclinical or overt hypothyroidism (data not shown).

The exclusion of the 39 subjects with a history of thyroid disease did not affect the results (data not shown).

\section{Discussion}

This study demonstrated a small, positive and significant relationship between BMI and serum TSH within the normal $\mathrm{TSH}$ range. In line with the present study, an association between BMI and TSH has been found in euthyroid subjects of recent population-based studies [16, 17].

However, the potential effect modifications on the association between BMI and serum TSH by race and menopause have not been previously reported. In this respect one strength of our study was the large population base as well as the ethnic mixture of the Brazilian population, which allowed for evaluating the effect of race on the relationship between BMI and TSH.

The plausibility of BMI-TSH relationship has been documented in other reports $[18,19]$, based on the many associations of TSH with hormones controlling weight change such as leptin, insulin and adiponectin [20-22]. In addition, recent studies have shown that high levels of leptin are associated with development of autoimmune thyroid diseases, increasing the risk of subclinical or overt hypothyroidism [23, 24].

Although, our findings do not support the hypothesis that the association between BMI and TSH is mediated by a hypothyroid state, we found the strongest association between BMI and serum TSH among Blacks and smokers. Moreover,
Table 2. Weighted multivariate regression coefficients $(\beta)$ of linear models with BMI as dependent variable

Table 3. Weighted regression coefficients $(\beta)$ of linear models with BMI as dependent variable and log of TSH as independent variable adjusted by smoking status, race and menopause

\begin{tabular}{lrcl}
\hline & \multicolumn{1}{l}{$\beta$} & \multicolumn{1}{c}{$95 \%$ CI } & p value* \\
\hline Log of TSH & 0.87 & $0.21-1.54$ & 0.001 \\
Smoking (yes/no) & -1.24 & -2.16 to -0.31 & 0.009 \\
Menopause (premenopausal/postmenopausal) & 1.27 & $0.22-2.32$ & 0.02 \\
Race (Black/Non-Black) & -0.69 & -1.67 to 0.28 & 0.17 \\
\hline
\end{tabular}

*Adjusted for variables in the table, and by age, and age squared.

\begin{tabular}{lccc}
\hline & $\beta$ & $95 \%$ CI & p value* \\
\hline Smoking (adjusted by race and menopause) & & & \\
$\quad$ No & 0.59 & -0.14 to 1.33 & 0.11 \\
$\quad$ Yes & 1.78 & $0.06-3.50$ & 0.04 \\
\hline Race (adjusted by smoking and menopause) & & & \\
$\quad$ Black & 1.39 & -0.44 to 3.22 & 0.14 \\
$\quad$ Non-Black & 0.79 & $0.08-1.50$ & 0.03 \\
\hline Menopausal status (adjusted by race and smoking) & & & \\
$\quad$ Premenopausal & 1.04 & $0.03-2.05$ & 0.04 \\
$\quad$ Postmenopausal & 0.70 & -0.20 to 1.60 & 0.13 \\
\hline
\end{tabular}

*All regression models were also adjusted by age and age squared. 
in these subgroups a lower prevalence of thyroid peroxidase antibodies was observed [5-7], and the association between BMI and TSH was no longer significant among women with higher levels of anti-TPO or overt hypothyroidism. These findings suggest that variations in TSH concentration, mainly in euthyroid subjects, could lead to body weight changes independent of its effect on thyroid function. In agreement with this finding, TSH receptor has been detected at the surface of both preadipocytes and adipocytes, and it was shown that TSH can directly stimulate preadipocyte differentiation, thereby inducing adipogenesis [25].

In the present study, when the analysis was categorized according to smoking status, a significant association between BMI and TSH was found only among smokers. This finding contrasts with those of Makepeace et al. [3] who reported no significant association between BMI and TSH in any of the smoking groups. However, these authors found a negative and significant association between BMI and free T4 among never and former smokers. Our results also differ from those of Nyrnes et al [2] who found a positive and significant association between BMI and TSH only among non-smokers, but the study included a lower number of smokers. In contrast, a recent study carried out in Norway showed a positive and significant association between BMI and TSH among never smokers and current smokers, and this association was stronger among men who were current smokers [16].

The analysis stratified by race (Blacks/Non-Blacks) revealed a stronger association among Black women; however this association was not statistically significant. This nonsignificant association may be due to the small sample size
( $\mathrm{n}=187$ ). To our knowledge, there is only one published study that evaluated the possible effect modification of race, but the study sample was predominantly Caucasian (330/401), and no correlation was found between BMI and TSH in any skin color group [4].

Of the three effect modifications studied, menopause was the factor with the smallest effect. We expected that the association between BMI and TSH was higher among postmenopausal women [12], but we only found a small effect when compared to premenopausal women. A possible explanation is that other factors such as reduced energy expenditure in postmenopausal women are stronger for weight gain, blurring a possible effect of TSH.

Limitations of our study include the fact that free T4 was only measured in women whose TSH concentration were out of the normal range; furthermore, free triiodothyronine levels were not measured. However, serum TSH concentrations have been considered the most sensitive marker of thyroid function [26].

In conclusion, BMI was positively associated with serum $\mathrm{TSH}$, especially in the normal TSH range. Smoking and race were strong effect modifiers of this association. A possible explanation are the changes in thyroid antibody levels as a function of race and smoking status. Future studies should take these factors into account.

\section{Disclosure Statement}

The authors declared no conflict of interest.

\section{References}

1 Knudsen N, Laurberg P, Rasmussen LB, Bulow I, Perrild H, Ovesen L, Jorgensen T: Small differences in thyroid function may be important for body mass index and the occurrence of obesity in the population. J Clin Endocrinol Metab 2005;90: 4019-4024.

2 Nyrnes A, Jorde R, Sundsfjord J: Serum TSH is positively associated with BMI. Int J Obes (Lond) 2006;30:100-105.

$\checkmark 3$ Makepeace AE, Bremner AP, O'Leary P, Leedman PJ, Feddema P, Michelangeli V, Walsh JP: Significant inverse relationship between serum free $\mathrm{t} 4$ concentration and body mass index in euthyroid subjects: Differences between smokers and nonsmokers. Clin Endocrinol (Oxf) 2008;69:648-652.

$\checkmark 4$ Manji N, Boelaert K, Sheppard MC, Holder RL, Gough SC, Franklyn JA: Lack of association between serum TSH or free T4 and body mass index in euthyroid subjects. Clin Endocrinol (Oxf) 2006;64: 125-128.

$\checkmark 5$ Belin RM, Astor BC, Powe NR, Ladenson PW: Smoke exposure is associated with a lower prevalence of serum thyroid autoantibodies and thyrotropin concentration elevation and a higher prevalence of mild thyrotropin concentration suppression in the Third National Health and Nutrition Examination Survey (NHANES III). J Clin Endocrinol Metab 2004;89:6077-6086.
-6 Sichieri R, Baima J, Marante T, de Vasconcellos MT, Moura AS, Vaisman M: Low prevalence of hypothyroidism among black and mulatto people in a population-based study of Brazilian women. Clin Endocrinol (Oxf) 2007;66:803-807.

7 Hollowell JG, Staehling NW, Flanders WD, Hannon WH, Gunter EW, Spencer CA, Braverman LE: Serum TSH, T(4), and thyroid antibodies in the United States population (1988 to 1994): National Health and Nutrition Examination Survey (NHANES III). J Clin Endocrinol Metab 2002;87: 489-499.

8 Aoki Y, Belin RM, Clickner R, Jeffries R, Phillips L, Mahaffey KR: Serum TSH and total T4 in the United States population and their association with participant characteristics: National Health and Nutrition Examination Survey (NHANES 19992002). Thyroid 2007;17:1211-1223.

$\checkmark$ Lewis TT, Everson-Rose SA, Sternfeld B, Karavolos K, Wesley D, Powell LH: Race, education, and weight change in a biracial sample of women at midlife. Arch Intern Med 2005;165:545-551.

10 Baum CL, Ruhm CJ: Age, socioeconomic status and obesity growth. J Health Econ 2009;28:635648 .
11 Marqusee E, Braverman LE, Lawrence JE, Carroll JS, Seely EW: The effect of droloxifene and estrogen on thyroid function in postmenopausal women. J Clin Endocrinol Metab 2000;85:4407-4410.

12 Abdel-Dayem MM, Elgendy MS: Effects of chronic estradiol treatment on the thyroid gland structure and function of ovariectomized rats. BMC Res Notes 2009;2:173.

13 Lohman TG, Roche AF, Martorell R: Anthropometric Standardization Reference Manual. Champaign, Human Kinetics Books, 1988

14 World Health Organization: Obesity: Preventing and managing the global epidemic. Report of a WHO Consultation. WHO Technical Report Series 894. Geneva, World Health Organization, 2000.

15 World Health Organization: Scientific Group on Research on the Menopause in the 1990s. WHO Technical Report Series. Geneva, WHO, 1996, pp $1-107$.

16 Asvold BO, Bjoro T, Vatten LJ: Association of serum TSH with high body mass differs between smokers and never-smokers. J Clin Endocrinol Metab 2009;94:5023-5027.

17 Ruhla S, Weickert MO, Arafat AM, Osterhoff M, Isken F, Spranger J, Schofl C, Pfeiffer AF, Mohlig M: A high normal TSH is associated with the metabolic syndrome. Clin Endocrinol (Oxf) 2009; DOI: $\underline{10.1111 / \mathrm{j} .1365-2265.2009 .03698 . x}$ 
18 Sorisky A, Bell A, Gagnon A: TSH receptor in adipose cells. Horm Metab Res 2000;32:468-474.

19 Valyasevi RW, Harteneck DA, Dutton CM, Bahn RS: Stimulation of adipogenesis, peroxisome proliferator-activated receptor-gamma (PPARgamma), and thyrotropin receptor by PPARgamma agonist in human orbital preadipocyte fibroblasts. J Clin Endocrinol Metab 2002;87:2352-2358.

20 Iacobellis G, Ribaudo MC, Zappaterreno A, Iannucci CV, Leonetti F: Relationship of thyroid function with body mass index, leptin, insulin sensitivity and adiponectin in euthyroid obese women. Clin Endocrinol (Oxf) 2005;62:487-491.
21 Michalaki MA, Vagenakis AG, Leonardou AS, Argentou MN, Habeos IG, Makri MG, Psyrogiannis AI, Kalfarentzos FE, Kyriazopoulou VE: Thyroid function in humans with morbid obesity. Thyroid 2006;16:73-78.

22 Ruscica M, Dozio E, Gandini S, Gnocchi P, Devalle GG, Motta M, Roti E, Magni P: Total, free and bound leptin and thyroid function in elderly women with different body weights. Clin Endocrinol (Oxf) 2008;68:1002-1008.

23 Biondi B: Thyroid and obesity: an intriguing relationship. J Clin Endocrinol Metab;95:3614-3617.
24 Marzullo P, Minocci A, Tagliaferri MA, Guzzaloni G, Di Blasio A, De Medici C, Aimaretti G, Liuzzi A: Investigations of thyroid hormones and antibodies in obesity: leptin levels are associated with thyroid autoimmunity independent of bioanthropometric, hormonal, and weight-related determinants. J Clin Endocrinol Metab;95:3965-3972.

$25 \mathrm{Lu} \mathrm{M}$, Lin RY: TSH stimulates adipogenesis in mouse embryonic stem cells. J Endocrinol 2008;196: 159-169.

26 Fox CS, Pencina MJ, D'Agostino RB, Murabito JM, Seely EW, Pearce EN, Vasan RS: Relations of thyroid function to body weight: cross-sectional and longitudinal observations in a communitybased sample. Arch Intern Med 2008;168:587-592. 